\title{
Effects of polyurethane foam on the behaviour of collapsible soils
}

Ahmed S. Abdulrasool PhD

Lecturer, Department of Civil Engineering, University of Technology - Iraq Baghdad, Iraq (Orcid:0000-0003-1837-4513)
Saad F. A. Al-Wakel PhD

Assistant Professor (Academic Staff), Department of Civil Engineering, University of Technology - Iraq, Baghdad, Iraq (Orcid:0000-0002-23040924) (corresponding author: saad.f.abbas@uotechnology.edu.iq; saadfaik231@gmail.com)

Collapsible soils such as gypseous soil are problematic in geotechnical engineering because their volume changes significantly upon saturation. Foundations constructed on gypseous soil undergo sudden and large settlement if the underlying soil experiences unanticipated moisture. The present study aims to improve the gypseous soil behaviour so that it can be used to support shallow foundations. To understand the mechanisms of stabilisation better, a laboratory study is performed to evaluate how polyurethane foam in different amounts influences the volumetric strain, collapse potential and mechanical behaviour of gypseous soil. Physical models of a footing on treated gypseous soil with polyurethane foam are examined to determine the effective treatment zone. Based on the obtained results, $3 \%$ polyurethane foam can be recommended to improve the gypseous soil behaviour; the particular reason is its effectiveness in decreasing the change in volumetric strain and collapse potential. The present study develops a theoretical approach that depends on a non-dimensional parameter to predict the ultimate bearing capacity for a footing on the surface of treated gypseous soil using the existing conventional theories.

Keywords: chemical ground improvement/footings/foundations/models (physical)

$\begin{array}{ll}\text { Notations } \\ B & \text { width of footing } \\ C_{\mathrm{c}} & \text { curvature coefficient } \\ C_{\mathrm{p}} & \text { collapse potential } \\ C_{\mathrm{u}} & \text { uniformity coefficient } \\ D_{50} & \text { median grain size } \\ e_{0} & \text { initial void ratio } \\ e_{1} & \text { equilibrium void ratio before saturation } \\ e_{2} & \text { equilibrium void ratio after saturation } \\ G_{\mathrm{S}} & \text { specific density } \\ k & \text { coefficient of permeability } \\ N_{\mathrm{c}} \text { and } N_{\gamma} & \text { bearing capacity factors } \\ q & \text { theoretical ultimate bearing capacity of untreated } \\ & \text { dry soil } \\ q_{\mathrm{T}} & \text { theoretical ultimate bearing capacity of treated soil } \\ R_{\mathrm{BC}} & \text { bearing capacity ratio } \\ S & \text { settlement of foundation } \\ S_{\mathrm{c}} \text { and } s_{\gamma} & \text { shape factors } \\ \gamma_{\mathrm{dry}} & \text { dry unit weight } \\ \gamma_{\mathrm{dry}} \text { max } & \text { maximum dry unit weight } \\ \gamma_{\mathrm{dry}} \text { min } & \text { minimum dry unit weight } \\ \Delta e & \text { change in void ratio } \\ \Delta \varepsilon & \text { change in volumetric strain } \\ \sigma_{\mathrm{w}}^{\prime} & \text { inundation stress } \\ \phi & \text { angle of internal friction } \\ & \end{array}$

\section{Introduction}

Soils can be problematic in geotechnical applications because they collapse, undergo excessive settlement and have a distinct loss of strength or solubility (Bell and Culshaw, 2001); one of these soils is the collapsible soil. Clemence and Finbar (1981) defined the collapsible soil as any unsaturated soil that goes through a radical rearrangement of particles and great loss of volume upon wetting with or without additional loading.

In general, sudden changes in volume develop in collapsible soils, which leads to collapse due to the increase in their moisture contents with or without loading; this occurs when the degree of saturation reaches above 50\% (Abbeche et al., 2010). In this regard, Lawton et al. (1992) pointed out that the collapsible soils are susceptible to large volumetric strains when they become saturated. Bell (2000) asserted that the increase in moisture content is the primary mechanism that triggers the volume reduction of collapsible soils. The collapsible soil structure means that it has low mass density and false rigidity when dry but undergoes large deformation upon wetting (Silveira and Rodrigues, 2020). It is worth noting here that one of the several types of collapsible soil is gypseous soil, and this type of soil is usually found in arid and semi-arid areas (Boyadgiev and Verheye, 1996).

The soil collapse potential, $C_{\mathrm{p}}$, is the most influential factor considered to achieve economically feasible and safe foundation on collapsible soils (Kalantari, 2013). Jennings and Knight (1975) presented a method based on oedometer tests to determine the collapse potential upon wetting, where the simple oedometer tests involve soaking at a specific load.

Several investigations have proposed various methods to improve the gypseous soil performance, but the techniques that have been developed to date cannot be used properly in the field. Some of these methods involve mechanical stabilisation using compaction 
(Lutenegger, 1986; Silveira and Rodrigues, 2020). This technique can be used when the wetting depth is $\sim 1.5-2 \mathrm{~m}$.

The other method is chemical stabilisation; many researchers have used this technique to improve the collapsible soil properties. O'Flaherty (1988) studied the effect of cement material on the collapsible soil behaviour; Parto and Kalantari (2011) used different types of admixture cement along with polypropylene fibres to stabilise collapsible soil. Lime stabilisation is the most commonly used technique to enhance the geotechnical properties of collapsible soil (Aldaood et al., 2014).

In many cases, chemically stabilised collapsible soils can be transformed into problematic soils during their service life. With time, the characteristics of lime-stabilised gypseous soils can be affected by environmental conditions and cause damage to the pavement structures founded on those soils due to the formation of expansive minerals that cause the swell of soil and crack formation (Aldaood et al., 2021). Semkin et al. (1986) stabilised loessial soil chemically using a carbon dioxide-sodium silicate-carbon dioxide injection scheme. The rising of groundwater can affect the effectiveness of stabilisation because carbon dioxide is soluble in water. Haeri and Valishzadeh (2021) presented a laboratory study to investigate the effect of using nano-calcium carbonate, nano-silica and nano-clay on the properties of collapsible soils.

All the previous studies have not dealt with a comprehensive analysis of all the main effects of material treatment on the change in volumetric strain and bearing capacity; each study analysed a few aspects of the treated soil behaviour, focusing only on the effectiveness of the treatment to improve the soil behaviour. However, in view of on-site applications, it is necessary to consider the changes in volumetric strain and bearing capacity as a consequence of treatment

The present study involves a detailed investigation of the behaviour of gypseous soil treated for the first time with polyurethane foam $(\mathrm{PF})$, which can be used in a liquid state. Experimental tests are performed to study how PF affects the volumetric strain, collapse potential and strength of gypseous soil. The literature to date contains no investigations of the bearing capacity behaviour of footings on collapsible soils where improvement is necessary. A theoretical approach is also presented to determine the theoretical ultimate capacity of foundations on treated collapsible soils.

\section{Experimental program and materials}

Samples of untreated and treated gypseous soil were tested to evaluate the effect of PF on the behaviour of soil. A more comprehensive range of $\mathrm{PF}$ content $(0,0.75,1,3$ and $5 \%)$ was used in performing oedometer tests to investigate how PF treatment affected the soil volumetric strain and collapse potential, which were considered an important aspect in this study. Furthermore, the same range of PF content was used to perform California bearing ratio (CBR) tests to investigate how the $\mathrm{PF}$ treatment affected the strength of the gypseous soil. The effect of the optimum value of PF on the bearing capacity behaviour of the gypseous soil was also investigated.
A natural gypseous soil with a gypsum content of $30 \%$, classified as highly gypsiferous (Barazanji, 1973), was used for all the tests. The grain size distribution of the soil is shown in Figure 1. This soil is mainly sand classified as SP according to the Unified Soil Classification System, which is characterised by a specific density, $G_{\mathrm{s}}$, of 2.4, a coefficient of uniformity, $C_{\mathrm{u}}$, of 5.3 and a coefficient of curvature, $C_{\mathrm{c}}$, of 1.3 . The physical properties of the soil are given in Table 1. The direct shear test was conducted on the untreated and treated gypseous soil with $\mathrm{PF}$ in liquid state according to ASTM D3080-98 (ASTM, 1998) specifications; the strength parameters are shown in Table 2.

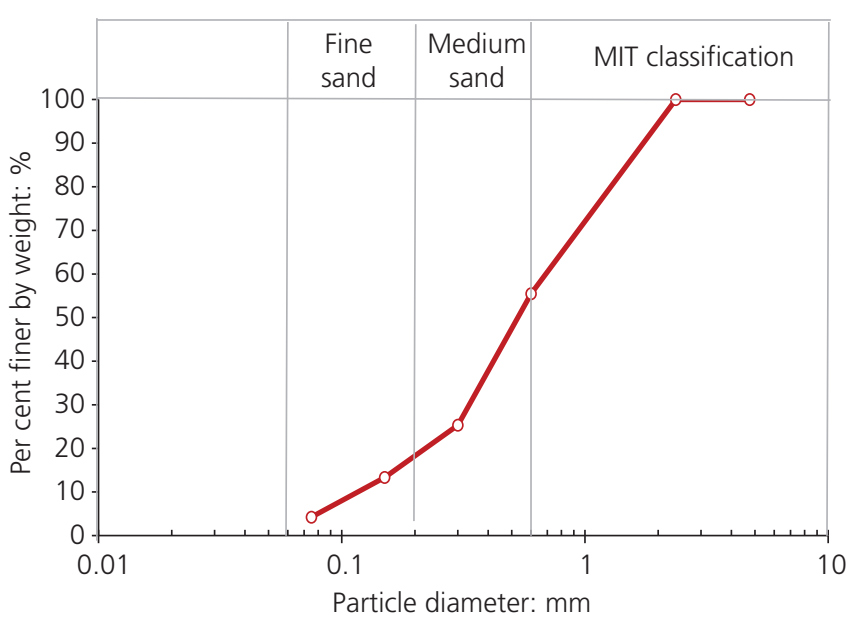

Figure 1. Grain size distribution of gypseous soil. MIT, Massachusetts Institute of Technology

Table 1. Physical properties of gypseous soil

\begin{tabular}{lc} 
Property & Value \\
\hline Maximum dry unit weight, $\gamma_{\text {dry max }}: \mathrm{kN} / \mathrm{m}^{3}$ & 13.87 \\
Minimum dry unit weight, $\gamma_{\text {dry min }}: \mathrm{kN} / \mathrm{m}^{3}$ & 11.42 \\
Median grain size, $D_{50}: \mathrm{mm}$ & 0.51 \\
Dry unit weight, $\gamma_{\text {dry }}: \mathrm{kN} / \mathrm{m}^{3}$ & 13.2 \\
Coefficient of permeability, $\mathrm{k}: \mathrm{cm} / \mathrm{s}$ & 0.5 \\
Initial void ratio, $e_{0}$ & 0.783
\end{tabular}

Table 2. Strength parameters of untreated and treated gypseous soil

\begin{tabular}{|ccc|}
$\begin{array}{l}\text { Type of } \\
\text { soil }\end{array}$ & $\begin{array}{c}\text { Apparent cohesion, } \mathbf{c :} \\
\mathbf{k N} / \mathbf{m}^{2}\end{array}$ & $\begin{array}{c}\text { Angle of internal } \\
\text { friction, } \boldsymbol{\phi}:^{\circ}\end{array}$ \\
\hline $\begin{array}{l}\text { Untreated } \\
\text { Treated, }\end{array}$ & 4 & 34 \\
$1 \% \mathrm{PF}$ & 9 & 33.8 \\
Treated, & 12 & 33.6 \\
$3 \% \mathrm{PF}$ & & \\
Treated, & 16 & 32 \\
$5 \% \mathrm{PF}$ & & \\
\hline
\end{tabular}


PF resins are used widely to stabilise mines and tunnels because they offer strong adhesion and firm foam. They are also used to stabilise disintegrated rock with a high void content and to fill smaller cavities. PF is supplied as a clear solution. It is a fastfoaming and solvent-free water-reactive polyurethane injection foam resin; thus, it can be injected as a liquid that then foams and expands to fill voids and smaller cavities in soil. Table 3 gives the properties of the PF material.

\section{One-dimensional confined compression test}

The behaviour of the treated gypseous soil with a PF content in the range $0.75-5 \%$ by weight of the dry soil was investigated. A reconstitution method was used to obtain the specimens for the test. Based on the dry unit weight of the soil specified previously, the mass of the gypseous soil required to fill a specified volume of the oedometer cell ring was determined. Then, the specimen was formed by tamping the soil in the form of three equal layers into a rigid confining ring, which did not allow any lateral displacement of the soil sample during the process of compaction or loading, to achieve the initial void ratio of 0.783 with a unit weight of $13.2 \mathrm{kN} / \mathrm{m}^{3}$. For the treated gypseous soil specimens, each prepared soil was mixed thoroughly with the required amount of $\mathrm{PF}$ in a liquid state by the weight of the dry soil and then compacted with three equal layers into the rigid ring.

A one-dimensional confined compression test (oedometer test) was performed by applying different loads and measuring the deformation response to a change in effective stress according to the ASTM D5333-03 (ASTM, 2003) specifications.

In the consolidation tests, step loads were applied to the soil up to an inundation stress, $\sigma^{\prime}{ }_{w}$, of $200 \mathrm{kPa}$, at which the equilibrium void ratio was $e_{1}$. At that pressure, water was introduced into the specimen for saturation and left for $24 \mathrm{~h}$, after which the equilibrium void ratio at the same inundation stress $\sigma^{\prime}{ }_{\mathrm{w}}$ was $e_{2}$. The change in volumetric strain due to saturation is given by

1. $\Delta \varepsilon=\frac{e_{1}-e_{2}}{1+e_{0}}=\frac{\Delta e}{1+e_{0}}$

where $\Delta \varepsilon$ is the change in volumetric strain, $\Delta e$ is the change in void ratio and $e_{0}$ is the initial void ratio.

For the treated soil, the PF material was added as a liquid; therefore, it was considered as a void in calculating the initial void ratio. Subsequently, collapse potential, $C_{\mathrm{P}}$, was determined at inundation stress $\left(\sigma^{\prime}{ }_{\mathrm{w}}=200 \mathrm{kPa}\right)$ using

Table 3. Specifications of polyurethane foam

\begin{tabular}{|llc|}
\hline Fibre properties & & Values \\
\hline Density (at $\left.20^{\circ} \mathrm{C}\right)$ & Part A & $1.01 \mathrm{~kg} / \mathrm{l}$ \\
& Part B & $1.23 \mathrm{~kg} / \mathrm{l}$ \\
Viscosity $\left(\right.$ at $\left.20^{\circ} \mathrm{C}\right)$ & Part A & $200 \mathrm{mPas}$ \\
& Part B & $250 \mathrm{mPas}$ \\
Mixing ratio & - & $1: 1$ by volume
\end{tabular}

2. $C_{\mathrm{p}}=\frac{\Delta H}{H_{0}} \times 100$

where $\Delta H$ is the change in the sample height and $H_{0}$ is the initial sample height. The values of the collapse potential according to ASTM D5333-03 (ASTM, 2003) specifications are given in Table 4.

\section{CBR test}

The pavement design is based on pavement thickness as a cover that depends on the subgrade soil with a given CBR value to accommodate higher traffic loads. Therefore, in this study, the CBR experiments were carried out to evaluate the gypseous soil stiffness when treated with different amounts of PF.

The CBR tests were conducted according to ASTM D1883-16 (ASTM, 2016a) specifications, using the bearing capacity at optimum water content only method. The penetration resistance of the soil was determined at the optimum water content determined from the compaction test according to specifications. The treated soil was cured for $24 \mathrm{~h}$ before the test to ensure the distribution of the moisture for CBR stabilisation.

The plunger penetration with a constant rate of $1.27 \mathrm{~mm} / \mathrm{min}$ was applied to the sample, and the load required to resist the plunger penetration was measured.

\section{Physical model}

Physical modelling is conducted to provide specific performance data for the design and analysis of footings on gypseous soil and to clarify the fundamental aspects of using PF for practical applications. The gypseous soil at the base of a structure can be exposed to moisture from several sources, such as broken water pipes, and the resulting settlement can cause considerable structural damage. Therefore, for such foundations, it is crucial to identify the settlement based on the ultimate bearing capacity (UBC).

Load tests were carried out on untreated $(\mathrm{PF}=0 \%)$ and treated $(\mathrm{PF}=$ $3 \%$ ) gypseous soil to investigate the effects of PF on the UBC of gypseous soil. The physical model comprised a rigid foundation modelled by a square footing of size $60 \times 60 \mathrm{~mm}$ in a steel container, with internal dimensions of $350 \mathrm{~mm}$ length, $350 \mathrm{~mm}$ width and $300 \mathrm{~mm}$ height, to avoid lateral yielding during the soil placement and loading of the foundation model.

Table 4. Collapse potential classification, according to ASTM D5333-03 (ASTM, 2003)

\begin{tabular}{|lc} 
Degree of specimen collapse & Collapse potential: \% \\
None & 0 \\
Slight & $0.1-2.0$ \\
Moderate & $2.1-6.0$ \\
Moderately severe & $6.1-10.0$ \\
Severe & $>10$
\end{tabular}


The boundary effects during the test can be avoided by considering that the length of the test container must not be less than five times the footing width, such that the rupture zones are free and the interference from the sides is negligible (Ueno et al., 1998). In this study, the maximum available extent for the rupture zone was $2.5 B$ on each side of the footing, and approximately $5 B$ below the footing, with $B$ being the width of footing. Moreover, during the test, the square footing selection reduced the dimensional effects (Adams and Collin, 1997).

At first, a $50 \mathrm{~mm}$ thick filter material was placed under the soil to prevent the erosion of soil particles while flooding the soil for saturation. The test container was filled with the soil of a total thickness of $240 \mathrm{~mm}$ divided into eight $30 \mathrm{~mm}$ thick layers for both treated and untreated soil using the dynamic compaction technique. For each layer, a specific volume of the container (a height of $30 \mathrm{~mm}$ with a cross-sectional area of the container) was filled with a mass of the soil, to satisfy a unit weight of $13.2 \mathrm{kN} / \mathrm{m}^{3}$ with the initial void ratio of 0.783 , then compacted to the required height.

To perform the bearing capacity tests of the treated soil, the gypseous soil was treated at three different depths under the footing: $0.5 B$ where the maximum strain in the soil occurred, $B$ and $2 B$ where the strain in the soil vanished. For each layer of the treated soil with a thickness of $30 \mathrm{~mm}$, a mass of the dry soil was mixed with the PF material in liquid state and compacted within a specific volume of the container to satisfy a unit weight of $13.2 \mathrm{kN} / \mathrm{m}^{3}$. In this definition, because the PF material was mixed in a liquid state, the volume contained both solid particles of the soil and voids between soil particles.

The footing was placed on levelled surface at a predefined alignment so that the applied load transferred concentrically to the footing. After immersing the soil with water, a load increment was applied at a constant rate to the foundation according to ASTM D1196-12 (ASTM, 2016b) specifications, and the settlement of footing under the effect of the applied load was recorded. The moisture content of saturated treated and untreated gypseous were 30 and $33 \%$, respectively.

In the design of the test model, a network of water pipes of $10 \mathrm{~mm}$ diameter was placed at a distance of $30 \mathrm{~mm}$ from the edge of the footing and at a depth of $30 \mathrm{~mm}$ to be outside the rupture zone. During flow, the boiling phenomenon was prevented by specifying the pipe discharge and the seepage velocity as $1.76 \mathrm{ml} / \mathrm{s}$ and $1.34 \mathrm{~cm} / \mathrm{s}$, respectively. The height of water in the container was monitored using a piezometer. The detailed section of the physical model is shown in Figure 2.

\section{Limitations}

The bearing capacity ratio $\left(R_{\mathrm{BC}}\right)$ presented in this study is based on a small-scale model, whereas the problems confronted in the field involve prototype foundations. Small-scale models are used widely to study the behaviour of full-scale foundations (Choudhary et al., 2010). The main differences between smallscale models and prototypes are their stress levels and the influence of the ratio of the footing width to the size of particles. Jha and Shukla (2015) stated that at low stress, the internal friction angle is higher than the friction angle at a higher stress level for granular soils, which is why the mobilised shear strength along a slip line under a foundation decreases with increasing footing size. The scale effect occurs in $1 \boldsymbol{g}$ modelling because of the variation in stress compared with the prototype. Although the use of small-scale models in predicting the behaviour of prototypes is limited, $1 \boldsymbol{g}$ modelling can be used to predict the general behaviour of foundations.

Another factor that should be considered is the scale effect due to the ratio of the footing width to the size of particles. For a footing

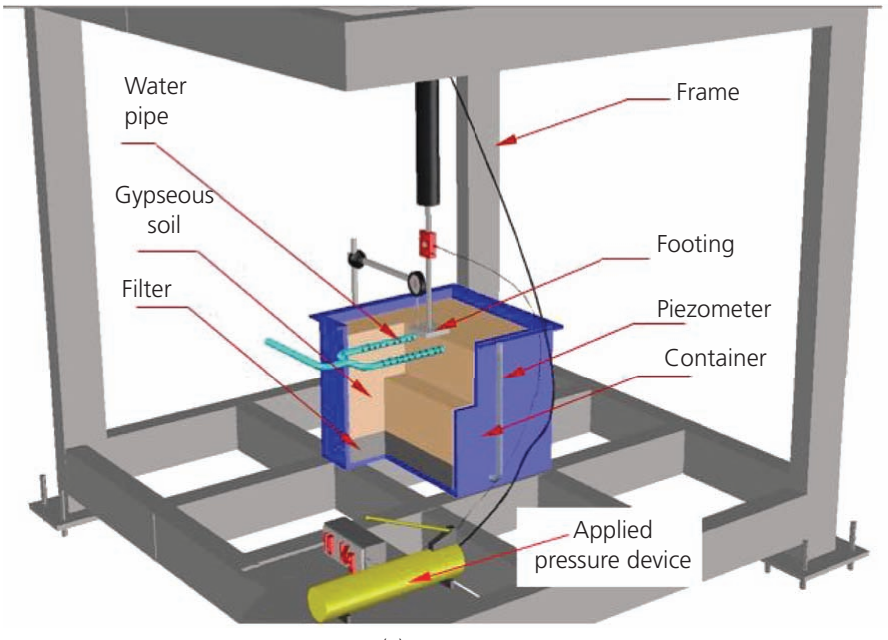

(a)

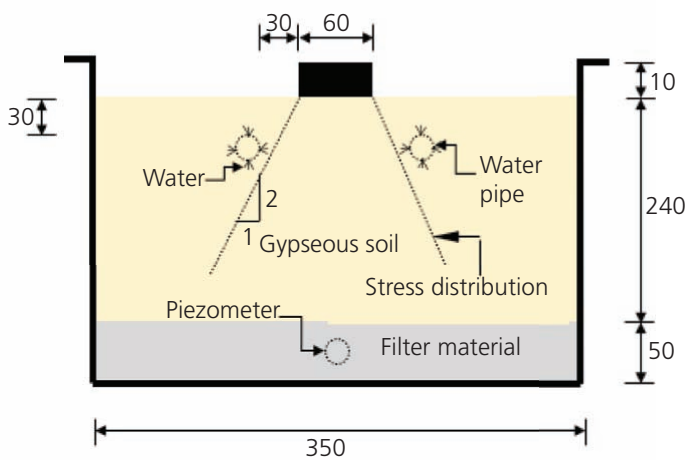

All dimensions in $\mathrm{mm}$

(b)

Figure 2. (a) Set-up and (b) section of physical model 
Effects of polyurethane foam on the

behaviour of collapsible soils

Abdulrasool and Al-Wakel subjected to central vertical loading, Okamura and Matsuo (2002) noted that the scale effect of the footing on the bearing capacity has been explored extensively by many experiments conducted at $1 \boldsymbol{g}$ as well as in geotechnical centrifuges. Ovesen (1979) investigated the scaling effects in centrifuge tests on models of footings in sand and found no scale effect on a footing model diameter $(D)$ or width $(B)$ larger than $30 D_{50}$. In the present study, the ratio $B / D_{50}$ was greater than 30 ; therefore, the influence of scale effects on the results of the physical model could be neglected.

\section{Results and discussion}

Compressibility and collapsibility behaviour

The results of the simple oedometer test on the samples of untreated gypseous soil shown in Figure 3 and gypseous soil treated with PF (Figures 4-7) are presented in the form of $e$ plotted against $\log \sigma^{\prime}$, where $e$ and $\sigma^{\prime}$ are the void ratio and effective stress, respectively. Each specimen behaved differently under additional load after saturation.

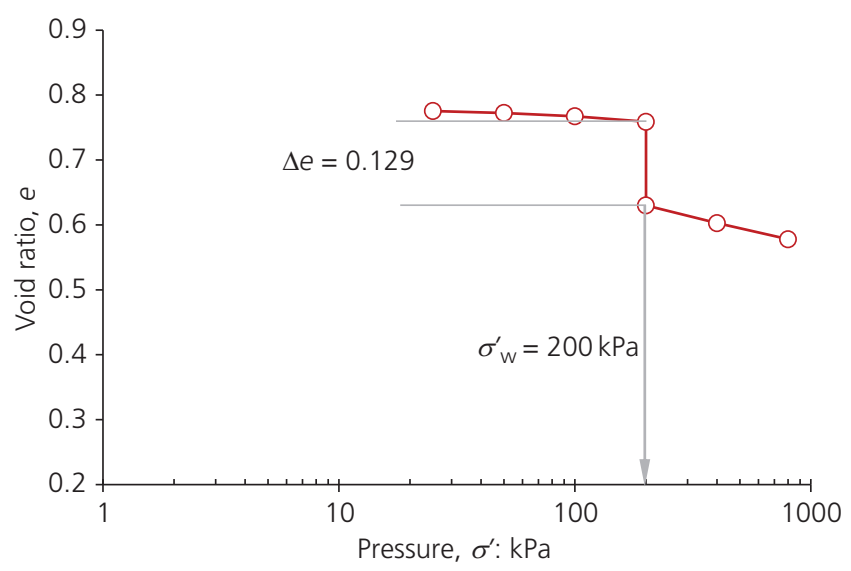

Figure 3. e plotted against log $\sigma^{\prime}$ from simple oedometer test on soil

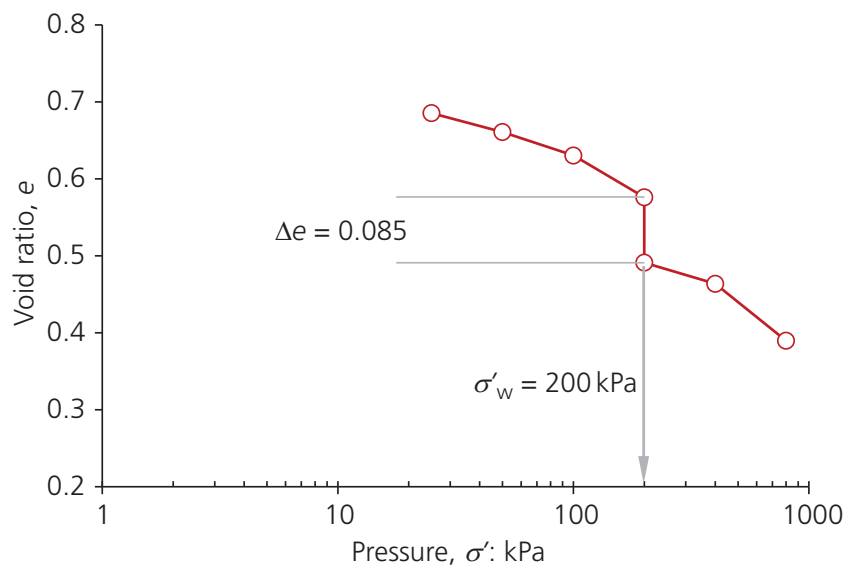

Figure 4. e plotted against log $\sigma^{\prime}$ from simple oedometer test on soil with $0.75 \%$ polyurethane foam (PF)

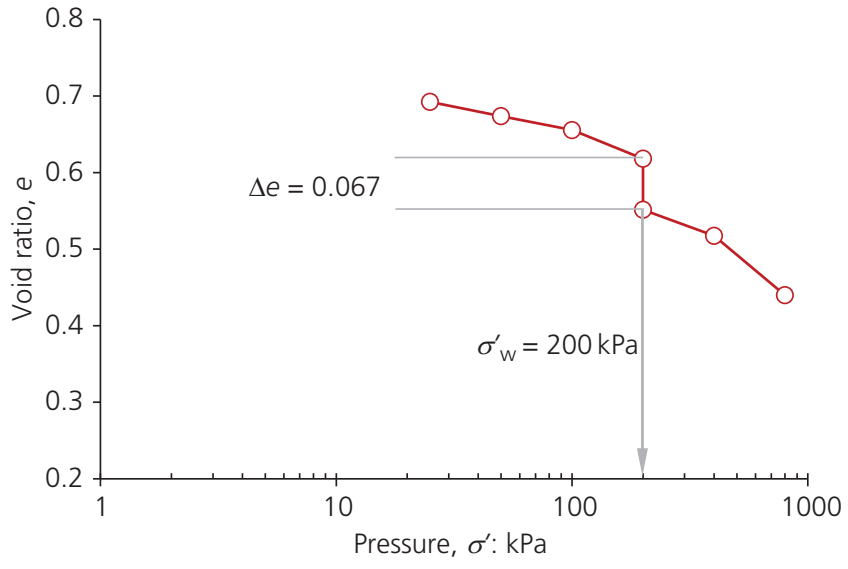

Figure 5. e plotted against log $\sigma^{\prime}$ from simple oedometer test on soil with $1 \% \mathrm{PF}$

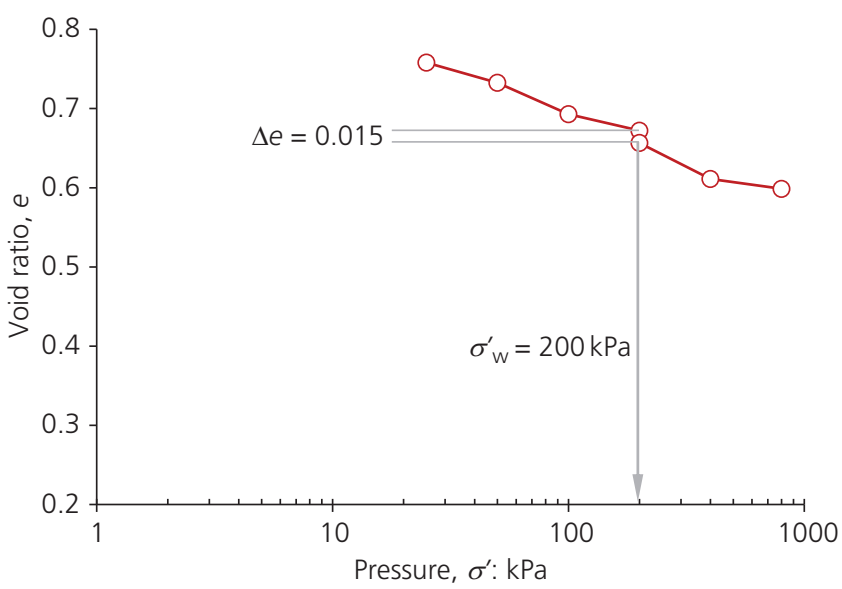

Figure 6. e plotted against log $\sigma^{\prime}$ from simple oedometer test on soil with 3\% PF

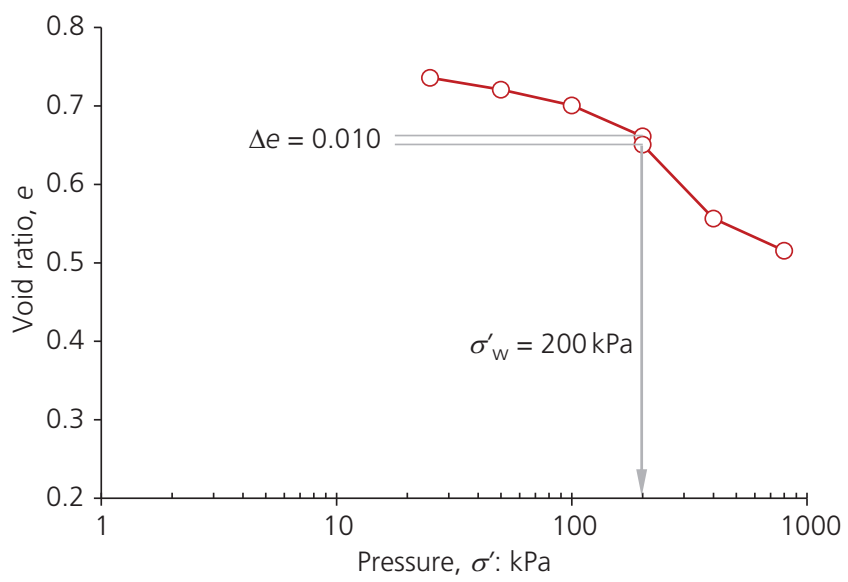

Figure 7. e plotted against $\log \sigma^{\prime}$ from simple oedometer test on soil with $5 \%$ PF 
Figure 8 shows how the PF treatment affected the change in the volumetric strain of the gypseous soil. As can be seen, the volumetric strain decreases with increasing $\mathrm{PF}$ content, and the optimum value of $3 \%$ is when the curve reaches an asymptotic value.

The results of the consolidation test show that the collapse potential changed from $C_{\mathrm{p}}=7.23 \%$ for the untreated soil to $C_{\mathrm{p}}=$ $0.84 \%$ for the soil treated with $3 \% \mathrm{PF}$. The values of $C_{\mathrm{P}}$ according to diverse criteria as given in Table 5 show that the collapsibility was improved from moderately severe to slight according to ASTM D5333-03 (ASTM, 2003).

From the results of the one-dimensional confined compression test, it can be observed that there was a higher void ratio change ( 0.7 to 0.4$)$ during pre-inundation loading for treated soil. This behaviour can be attributed to the fact that the PF material reacts

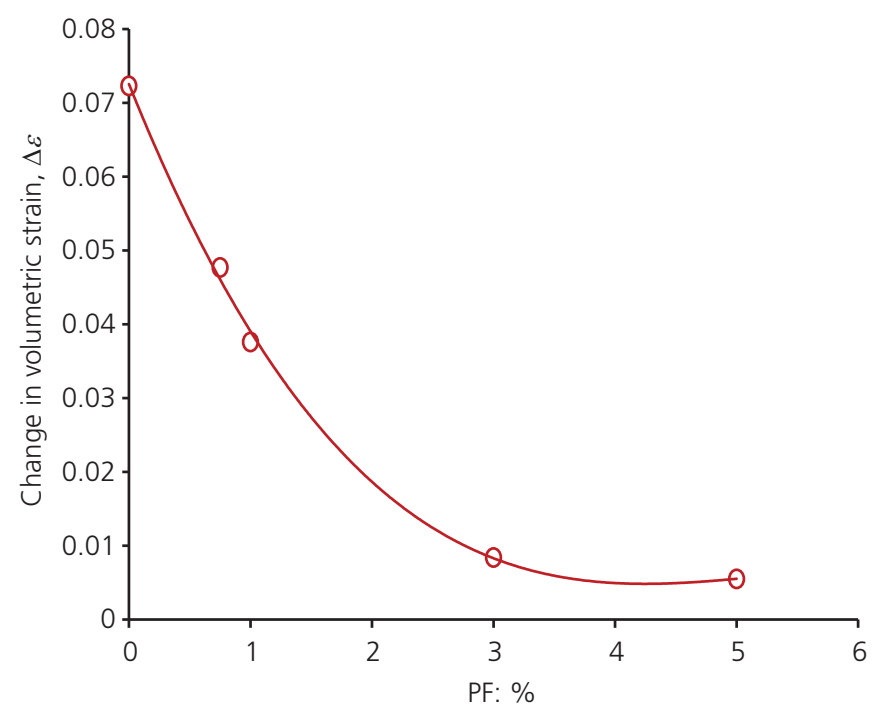

Figure 8. Change in volumetric strain of gypseous soil plotted against PF content

Table 5. Degree of collapse according to diverse criteria

\begin{tabular}{cccc}
$\begin{array}{c}\text { Type of } \\
\text { sample }\end{array}$ & $\begin{array}{c}\text { Collapse } \\
\text { potential: \% }\end{array}$ & \multicolumn{2}{c}{$\begin{array}{c}\text { Degree of collapse based on } \\
\text { different criteria }\end{array}$} \\
\cline { 3 - 4 } & $\begin{array}{c}\text { Jennings and } \\
\text { Knight (1975) }\end{array}$ & $\begin{array}{c}\text { ASTM D5333-03 } \\
\text { (ASTM, 2003) }\end{array}$ \\
$\begin{array}{c}\text { Untreated } \\
\text { Treated, } \\
0.75 \%\end{array}$ & 7.23 & $\begin{array}{c}\text { Trouble } \\
\text { Moderate }\end{array}$ & $\begin{array}{c}\text { Moderately severe } \\
\text { Moderate }\end{array}$ \\
$\begin{array}{c}\text { PF } \\
\text { Treated, } \\
1 \% \text { PF }\end{array}$ & 3.77 & Moderate & Moderate \\
$\begin{array}{c}\text { Treated, } \\
3 \% \text { PF }\end{array}$ & 0.84 & No problem & Slight \\
$\begin{array}{c}\text { Treated, } \\
5 \% \text { PF }\end{array}$ & 0.55 & No problem & Slight \\
\hline
\end{tabular}

with water and transforms to foam. In this case, it is considered as a solid particle in the voids; therefore, the value of the void ratio decreases due to the presence of those particles. This behaviour led to decrease in the permeability of the soil and an increase in the bearing capacity due to the cohesive effect between particles.

The collapse potential for gypseous soil with a moisture content of $33 \%$ was $7.23 \%$, while for treated gypseous soil $(\mathrm{PF}=3 \%$ ) with a moisture content of $30 \%$, the collapse potential was $0.84 \%$.

The penetration resistance of the soil samples according to the required force from the CBR test is shown in Figure 9. The CBR values corresponding to penetrations of 2.54 and $5.08 \mathrm{~mm}$ were calculated, and the larger value was taken as $\mathrm{CBR}_{\mathrm{LAB}}$. The analysis of the CBR test results in Figure 10 shows how the $\mathrm{CBR}_{\mathrm{LAB}}$ value of the gypseous soil varied with $\mathrm{PF}$ content. With the optimum moisture content, the $\mathrm{CBR}_{\mathrm{LAB}}$ value of the gypseous soil increased with increasing $\mathrm{PF}$ content. The increase was more rapid up to $1 \% \mathrm{PF}$, and then $\mathrm{CBR}_{\mathrm{LAB}}$ reached its asymptotic value after $3 \% \mathrm{PF}$.

\section{Bearing capacity behaviour}

In this study, the tangent intersection method was used to determine the bearing capacity of the foundation. Trautmann and Kulhawy (1998) used this method to determine the load that corresponds to a particular change in the settlement. Figure 11 shows the normalised load-settlement curves of the treated and untreated gypseous soil. As can be seen, the UBC of the foundation on saturated untreated gypseous soil is lower than that on dry and saturated treated gypseous soil. Moreover, the failure is transformed from punching shear failure (Figure 12) to general shear failure (Figure 13). This behaviour is due to the solvent of salts present in the gypseous soil upon saturation with water, which can affect the bonds between particles, resulting in soil dissolution and leading to possible subsidence and cavity formation.

The experimentally obtained results were analysed to determine a non-dimensional parameter called the bearing capacity ratio $\left(R_{\mathrm{BC}}\right)$. This parameter estimates the UBC of the footings on the surface of treated gypseous soil with $\mathrm{PF}$. The $R_{\mathrm{BC}}$ is defined as the ratio of the UBC of saturated treated gypseous soil $\left(q_{\mathrm{T}}\right)$ to that of dry untreated gypseous soil $\left(q_{\text {ult }}\right)$. According to the experimental data plotted in Figure 11, the values of $R_{\mathrm{BC}}$ are 0.5 , 0.75 and 0.8 for foundations on gypseous soil treated at depths of $0.5 B, B$ and $2 B$, respectively.

The theoretical UBC of a square footing on the surface of a dry soil can be calculated using the following equation (Terzaghi, 1943):

3. $q_{\mathrm{ult}}=c N_{\mathrm{c}} s_{\mathrm{c}}+0.5 \gamma B N_{\gamma} s_{\gamma}$ 


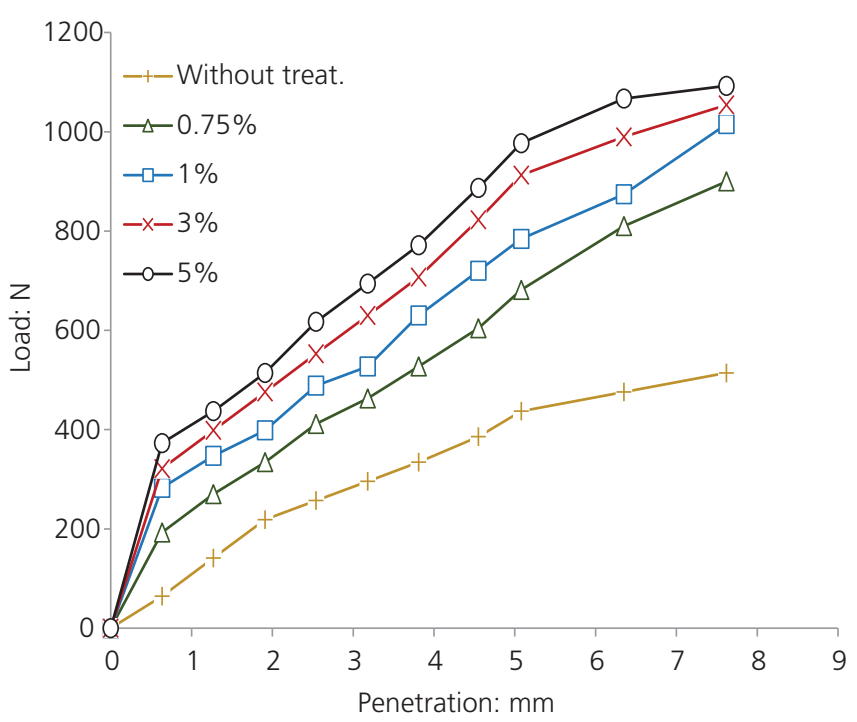

Figure 9. Load-against-penetration curves from CBR test on treated and untreated gypseous soil

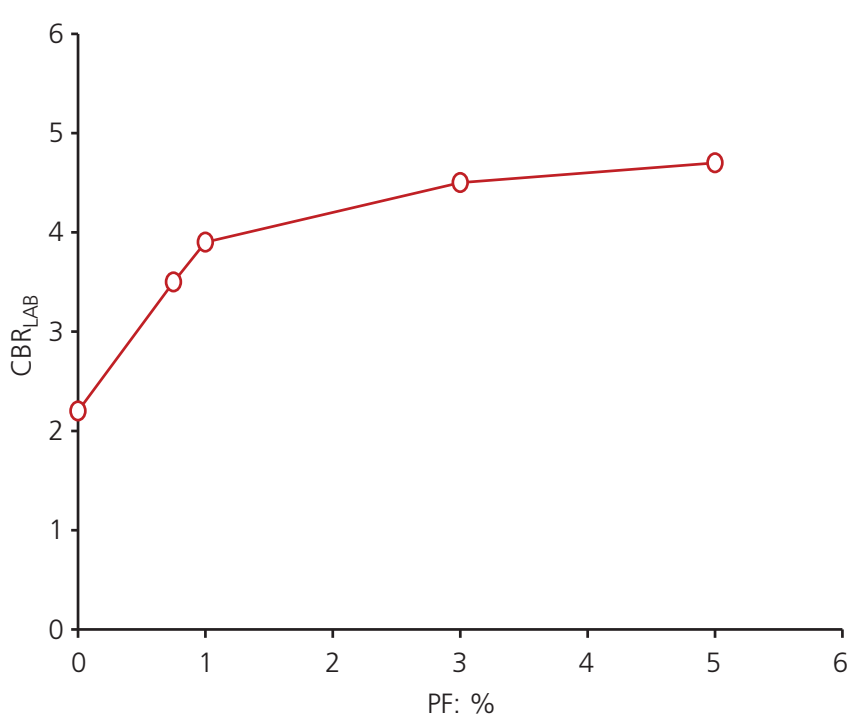

Figure 10. CBR of treated and untreated gypseous soil

The theoretical UBC of a square footing of different widths can be calculated by substituting the values of the shape factors, $s_{c}$ and $s_{\gamma}$ of a square footing and the bearing capacity factors, $N_{c}$ and $N_{\gamma}$. Based on the bearing capacity ratio, the theoretical UBC of the foundation on saturated treated soil can be related to that calculated from Equation 3 by using the bearing capacity ratio $\left(R_{\mathrm{BC}}\right)$ which depends on the treated layer depth. Accordingly, the ultimate bearing capacity of the saturated treated soil $\left(q_{\mathrm{T}}\right)$ can be calculated directly by multiplying a bearing capacity ratio $\left(R_{\mathrm{BC}}\right)$ by the bearing capacity of the footing $\left(q_{\mathrm{ult}}\right)$ :

4. $q_{\mathrm{T}}=R_{\mathrm{BC}} \cdot q_{\mathrm{ult}}$

\section{Effect of polyurethane foam}

The results obtained in this study indicate that treating gypseous soil with PF minimises the volumetric strain change compared with pure gypseous soil. The behaviour of gypseous soil in terms of collapse potential and strength improves when the soil is treated with PF. This behaviour can be attributed to the foam providing a water-proofing coat around the gypseous soil particles and preventing structural collapse under saturation. The foam also provides a cohesive bond between the gypseous soil particles.

\section{Practical applications}

The soil grouting with liquid materials could be recognised as a solution for gypseous soils at various depths in-site (Mori et al., 1989). Therefore, in view of practical applications to improve the behaviour of gypseous soil, polyurethane foam grouting is advisable because it allows the volumetric strain of the treated material to be minimised and reduces the collapse potential. From this study, $\mathrm{PF}=3 \%$ of the dry unit weight of the soil seems to be able to improve the behaviour of gypseous material under saturation and loading conditions; the collapsibility was improved from moderately severe to slight.

\section{Conclusions}

This paper has presented an alternative novel material for improving the collapsible soil behaviour. An experimental laboratory campaign and a physical model were used to analyse the main effects of treating collapsible soils with PF. The effectiveness of the treatment on the change in the volumetric strain of the soil was shown by a one-dimensional confined compression test (oedometer test). The effects of PF on the strength under the effect of static loading were then evaluated by means of a CBR test. Also, a physical model of footings on treated and untreated collapsible soil was used to provide a theoretical approach for the design and analysis. According to the obtained results, the following conclusions are drawn.

1. Filling the collapsible soil's pores with PF foam improves its behaviour under saturation and loading.

2. The results of the direct shear tests indicate that the PF liquid affects the shear strength parameters of the gypseous soil by increasing the apparent cohesion and the angle of internal friction relatively decreased.

3. The results of one-dimensional confined compression test showed that the change in volumetric strain of treated collapsible soil is less than the untreated soil, and 3\% PF content reduces the volumetric strain considerably.

4. The collapse potential of gypseous soil treated with $3 \% \mathrm{PF}$ is reduced to less than one, which generally means no problems for foundations.

5. Because the CBR of soil measured in the laboratory provides an index for the soil strength, the present study shows that $3 \%$ PF content is effective in collapsible soils. 
Effects of polyurethane foam on the

behaviour of collapsible soils

Abdulrasool and Al-Wakel

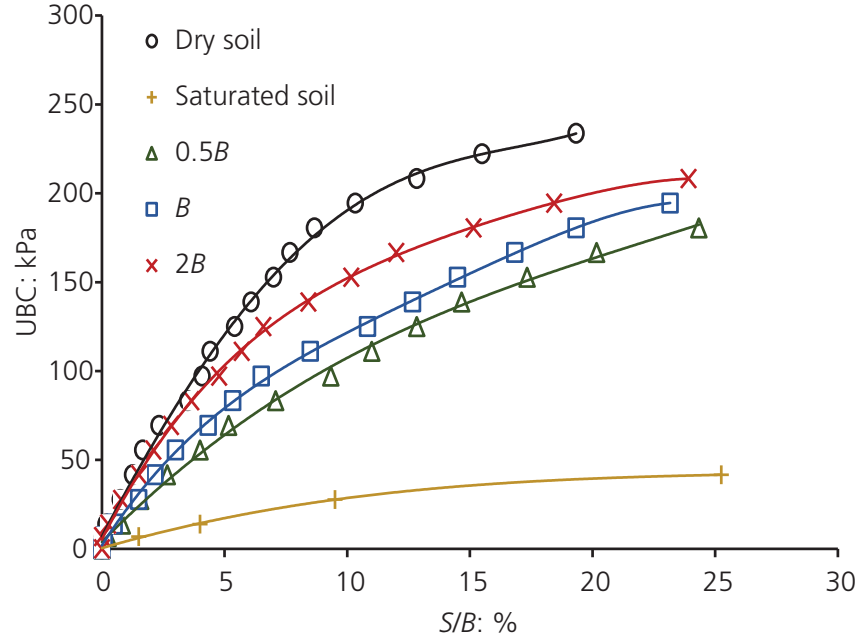

Figure 11. Normalised load-settlement curves of treated and untreated gypseous soil

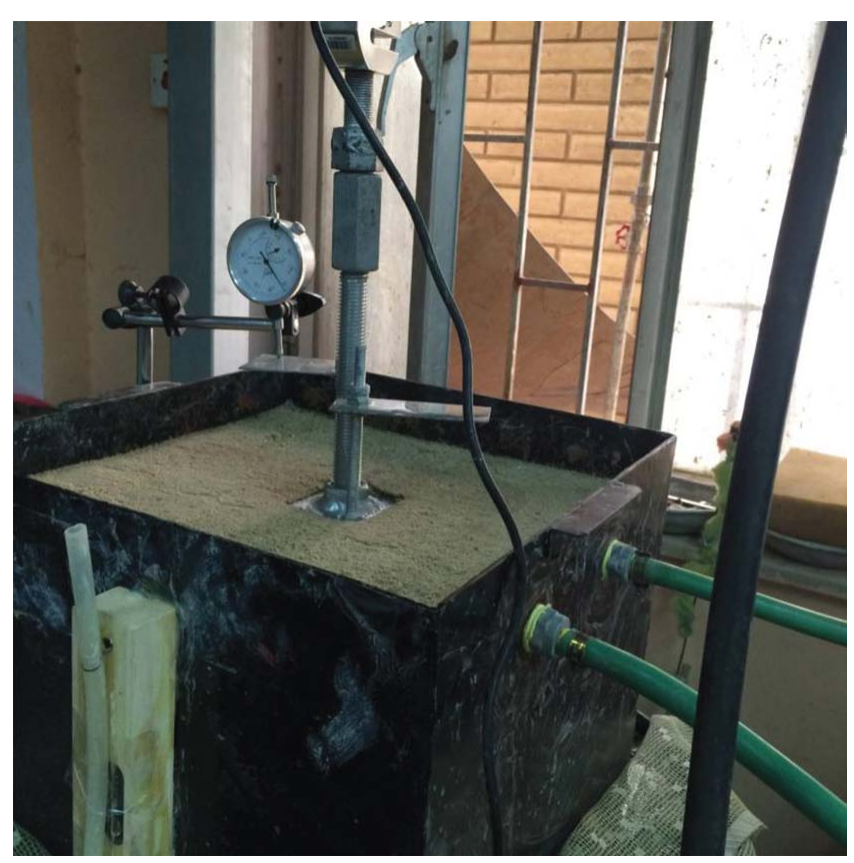

Figure 12. Bearing capacity test (punching shear failure)

6. There is a considerable increase in the value of the UBC of foundations when the underlying collapsible soil that is liable to moisture is treated with $3 \% \mathrm{PF}$. The increase in UBC depends on the depth of the effective treatment zone.

In conclusion, regarding practical applications, 3\% $\mathrm{PF}$ can be used to improve the behaviour of collapsible soils under saturation and loading, and the behaviour does not improve further significantly as the PF percentage is increased above this

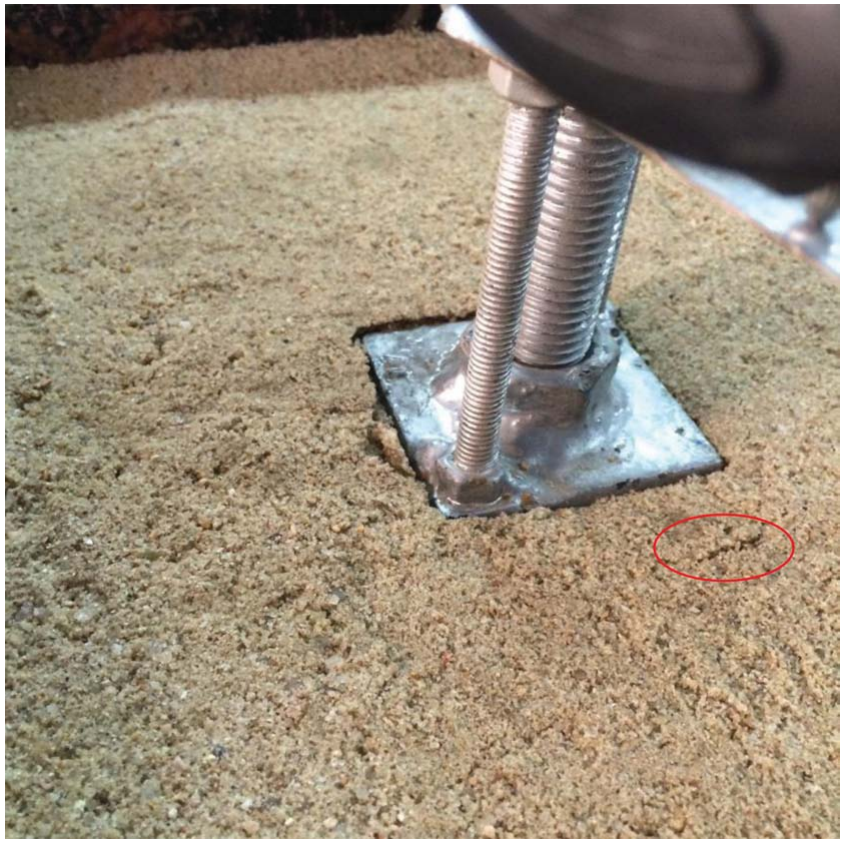

Figure 13. Bearing capacity test (general shear failure)

threshold. Also, it provides a theoretical approach to determining the theoretical UBC of footings on treated collapsible soils.

\section{REFERENCES}

Abbeche K, Bahloul O, Ayadat T and Bahloul A (2010) Treatment of collapsible soils by salts using the double consolidation method. In GeoShanghai 2010: Experimental and Applied Modeling of Unsaturated Soils (Hoyos LR, Zhang X and Puppala AJ (eds)). ASCE, Reston, VA, USA, GSP no. 202, pp. 69-78.

Adams MT and Collin JG (1997) Large model spread footing load tests on geosynthetic reinforced soil foundations. Journal of Geotechnical and Geoenvironmental Engineering - ASCE 123(1): 66-72, https://doi.org/ 10.1061/(ASCE)1090-0241(1997)123:1(66).

Aldaood A, Bouasker M and Al-Mukhtar M (2014) Geotechnical properties of lime treated gypseous soils. Applied Clay Science 88-89 39-48, https://doi.org/10.1016/j.clay.2013.12.015.

Aldaood A, Bouasker M and Al-Mukhtar (2021) Mechanical behavior of gypseous soil treated with lime. Geotechnical and Geological Engineering 39(2): 719-733, https://doi.org/10.1007/s10706-020-01517-w.

ASTM (1998) D3080-98: Standard test method for direct shear test of soils under consolidated drained conditions. Annual Book of ASTM

Standards, vol. 04.08. ASTM International, West Conshohocken, PA, USA, pp. 1-6.

ASTM (2003) D5333-03: Standard test method for measurement of collapse potential of soils (withdrawn 2012). ASTM International, West Conshohocken, PA, USA.

ASTM (2016a) D1883-16: Standard test method for California bearing ratio (CBR) of laboratory-compacted soils. ASTM International, West Conshohocken, PA, USA

ASTM (2016b) D1196/D1196M-12: Standard test method for nonrepetitive static plate load tests of soils and flexible pavement components, for use in evaluation and design of airport and highway pavements. ASTM International, West Conshohocken, PA, USA.

Barazanji AF (1973) Gypseous Soil of Iraq. PhD thesis, State University of Ghent, Ghent, Belgium. 
Effects of polyurethane foam on the

behaviour of collapsible soils

Abdulrasool and Al-Wakel
Bell FG (2000) Engineering Properties of Soils and Rocks. Blackwell Science, Oxford, UK

Bell FG and Culshaw MG (2001) Problem soils: a review from a British perspective. In Problematic Soils: Proceedings of the Symposium Held at the Nottingham Trent University (Jefferson I, Murray EJ, Faragher E and Fleming PR (eds)). Thomas Telford, London, UK, pp. 1-35.

Boyadgiev TG and Verheye WH (1996) Contribution to a utilitarian classification of gypsum in soils. Geoderma 74(34): 321-338, https:// doi.org/10.1016/S0016-7061(96)00074-2.

Choudhary AK, Jha JN and Gill KS (2010) Laboratory investigation of bearing capacity behavior of strip footing on reinforced fly ash slope. Geotextiles and Geomembranes 28(4): 393-402, https://doi.org/10. 1016/j.geotexmem.2009.09.007.

Clemence SP and Finbarr AO (1981) Design consideration for collapsible soils. Journal of Geotechnical Engineering Division ASCE 107(3): 305-317, https://doi.org/10.1061/AJGEB6.0001102.

Haeri SM and Valishzadeh R (2021) Evaluation of using different nanomaterials to stabilize the collapsible loessial soil. International Journal of Civil Engineering 19(5): 583-594, https://doi.org/10.1007/ s40999-020-00583-8.

Jennings JE and Knight K (1975) A guide to construction on or with materials exhibiting additional settlement due to collapse of grain structure. In Soil Mechanics and Foundation Engineering: Proceedings of the Sixth Regional Conference for Africa (Pells PJN and Robertson AMG (eds)). Balkema, Rotterdam, the Netherlands, pp. 99-105.

Jha JN and Shukla SK (2015) Bearing capacity and settlement characteristics of sand subgrades with vertical reinforcement supporting a square footing. International Journal of Geosynthetics and Ground Engineering 1(2): article 16, https://doi.org/10.1007/ s40891-015-0018-2.

Kalantari B (2013) Foundations on collapsible soils: a review. Proceedings of the Institution of Civil Engineers - Forensic Engineering 166(2): 57-63, https://doi.org/10.1680/feng.12.00016.

Lawton EC, Fragaszy RJ and Hetherington MD (1992) Review of wettinginduced collapse in compacted soil. Journal of Geotechnical
Engineering 118(9): 1376-1394, https://doi.org/10.1061/(ASCE)07339410(1992)118:9(1376).

Lutenegger AJ (1986) Dynamic compaction in friable loess. Journal of Geotechnical Engineering ASCE 112(6): 663-667, https://doi.org/10. 1061/(ASCE)0733-9410(1986)112:6(663).

Mori A, Tainura M and Fukui Y (1989) Distribution of grouts in solidified region in chemical grouts. Soils and Foundations 29(4): 127-134, https://doi.org/10.3208/sandf1972.29.4 127.

O'Flaherty CA (1988) Highways. Volume 2: Highway Engineering, 3rd edn. Edward Arnold Publishers Ltd, London, UK.

Okamura M and Matsuo O (2002) A displacement prediction method for retaining walls under seismic loading. Soils and Foundations 42(1): 131-138, https://doi.org/10.3208/sandf.42.131.

Ovesen NK (1979) The scaling law relationship. In Proceedings of the 7th European Conference on Soil Mechanics and Foundation Engineering. British Geotechnical Society, London, UK, vol. 4, pp. 319-323.

Parto P and Kalantari B (2011) Laboratory investigation on the effect of polypropylene fibers on the California bearing ratio of stabilized windblown sand. Electronic Journal of Geotechnical Engineering 16(Bundle R): 1369-1380.

Semkin VV, Ermoshin VM and Okishev ND (1986) Chemical stabilization of loess soils in Uzbekistan to prevent building deformations. Soil Mechanics and Foundation Engineering 23(5): 196-199, https://doi. org/10.1007/BF01711889.

Silveira IA and Rodrigues RA (2020) Collapsible behavior of lateritic soil due to compacting conditions. International Journal of Civil Engineering 18(10): 1157-1166, https://doi.org/10.1007/s40999-02000523-6.

Terzaghi K (1943) Theoretical Soil Mechanics. John Wiley \& Sons, New York, NY, USA.

Trautmann CH and Kulhawy FH (1988) Uplift load displacement behavior of spread foundations. Journal of Geotechnical Engineering 114(2): 168-184, https://doi.org/10.1061/(ASCE)0733-9410(1988)114:2(168).

Ueno K, Miura K and Maeda Y (1998) Prediction of ultimate bearing capacity of surface footings with regard to size effects. Soils and Foundations 38(3): 165-178, https://doi.org/10.3208/sandf.38.3_165.

\section{How can you contribute?}

To discuss this paper, please submit up to 500 words to the editor at journals@ice.org.uk. Your contribution will be forwarded to the author(s) for a reply and, if considered appropriate by the editorial board, it will be published as a discussion in a future issue of the journal. 